\title{
Using AquaCrop Model to simulate irrigation water use efficiency of potato crop under semi-arid conditions of Central Tunisia
}

\author{
Hiba Ghazouani ${ }^{1, *}$, Basma Latrech ${ }^{1}$, Boutheina M'hamdi Douh ${ }^{1}$, \\ Cherni Amani ${ }^{3}$, Mguidich Belhaj Amel $^{2}$, Ghazouani Issam ${ }^{3}$ and \\ Abdelhamid Boujelben ${ }^{1}$
}

\author{
${ }^{1}$ Department of Rural Engineering. Higher Institute of Agronomy. Chott-Mariem \\ Sousse (ISA-CM). Université de Sousse, 4042. Tunisia. *Email: \\ ghazouani_hibaunipaisa@yahoo.com. \\ ${ }^{2}$ Regional Field Crops Research Center (CRRGC). Béja. Tunisia. \\ ${ }^{3}$ University of Jendouba. Higher School of Agriculture of Kef. Kef. Tunisia.
}

\begin{abstract}
In Tunisia, water scarcity forces producers to face stress conditions. In this study, AquaCrop was used to reproduce the dynamic of water contents, vegetative growth, yield production and water use efficiency under a non-stressed and water stressed treatments. Calibration procedure aimed to use in maximum default parameters of AquaCrop. Since, the paper presented only the parameters that have to be adjusted to obtain similar results of field measurements. Root mean squared error, RMSE, values were always lower than $0.04 \mathrm{~cm}^{3} . \mathrm{cm}^{-3}$ for water contents lower than 0.06 for vegetation cover estimation. Moreover, results from Nasch Coefficient, E, were almost equal to one. RMSE and E justified that the model was well assessed to predict the soil water contents and vegetation development under the study area. However, the model presented a greater performance in the case of full irrigation strategy. When evaluating different values of water productivity, it was showed

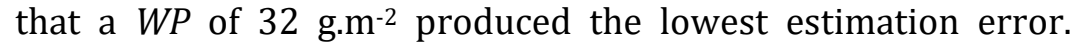
Regarding yield productions, statistical indictors, computed for a

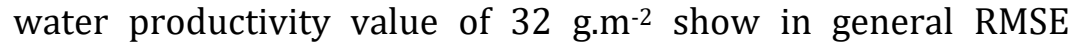
values lower than $0.4 \mathrm{t} / \mathrm{ha}$. In addition, $\mathrm{E}$ was closer to one for the non stressed treatment, T1. For irrigation water use efficiency, it was depicted that the model underestimated field IWUE. Moreover, the discrepancy between simulated and estimated irrigation water use efficiency rose for treatment T2, implying that the model calibration should be improved, especially for stressed conditions. The model, after being calibrated, could be used for simulating the response of the crop to different irrigation management aiming to optimize water use efficiency.
\end{abstract}

Keywords: Canopy development; Production; Water productivity; AquaCrop.
Received

April 6, 2019

Accepted

April 29, 2019

Released

April 30, 2019

Full Text Article

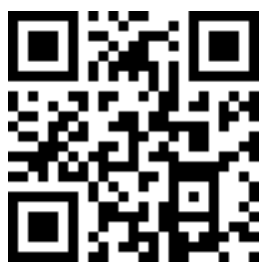

ORCID

(1) 0000-0002-4601-1528 Hiba Ghazouani

(1) 0000-0002-5790-0558 Basma Latrech

(D) 0000-0002-3439-2212 Boutheina M'hamdi Douh

D) 0000-0002-0729-588X Cherni Amani

(D) 0000-0002-1223-5312 Mguidich Belhaj Amel

(1) 0000-0002-7797-2671 Ghazouani Issam 


\section{Introduction}

In Tunisia, water resources are in a continuous decrease. Farmers are usually obliged to face situations of deficit irrigation allocation (DI). Although, DI has not been experimented under the semi-arid Tunisian conditions. In Tunisia, potato crop with more than 50 varieties, represents the second main crop, with a total surface of 27,000 ha $(7 \%$ of irrigated lands) and a total production of 360,000 t per year (Chehaibi et al., 2013). Several researchers consider that is difficult to manage deficit irrigation for potato crop because of the rapid effect of water stress (Wright and Stark, 1990; Shock et al., 1993; Eldredge et al., 1996). In that context, model simulations after calibration and validation, could be a powerful tool for testing the impact of different deficit irrigation strategies on final yield (Droogers and Hunink, 2012).

The FAO AquaCrop model allows investigating the effect of a biotic stress on final crop yield (Farahani et al., 2009). Several researchers have found satisfactory results with AquaCrop when simulating the effect of different soil humidity on plant growth and production for many crops like sunflower, beans, winter wheat and tomato (Kaysha et al., 2009). According to Farahani et al. (2009), AquaCrop is a simple model combining robustness and accuracy. Moreover, the model does not recommend numerous input parameters compared to other growth crop models. Since, model calibration does not require skilled researchers, especially with the existing set of default parameters by Hsiao et al. (2009). These conservative parameters overcome the influence of geographical site and crop cultivar (Steduto et al., 2009). Some researchers suggested even to not adjust these parameters since their modulation is dependent on the stress function.
0000-0002-3026-9014

Abdelhamid Boujelben
Actually, potato is between the most water demanding crops compared to arboreal or cereal. So that, the possibility to manage irrigation based on field measurement and site calibrated model could have a strong impact on increasing local productions.

Objective of the paper was to use a previously calibrated and validated model based on canopy cover and water contents for the simulation of yield production and irrigation water use efficiency under different irrigation management.

\section{Material and methods}

\section{Description of the study area and irrigation management}

Field Experiments were conducted at the High Agronomic Institute of Chott Meriem, Sousse, Tunisia (longitude $10.5632^{\circ} \mathrm{W}$; latitude $35.9191^{\circ} \mathrm{N}$, altitude $19.0 \mathrm{~m}$ a.s.l.), under a semi-arid climate, with hot and dry summer and mild-rainy winter seasons. Potato tuber seeds of the same potato cultivar (Solanum tuberosum L., cv. Safran), were planted on January, 15th and on January, 22nd, respectively, in 2014 and 2015. Distance along the row was equal to $0.40 \mathrm{~m}$ and $0.80 \mathrm{~m}$ between the rows, in an experimental plot, $25 \mathrm{~m}$ length and $7 \mathrm{~m}$ wide. The experimental plot was divided in two subplots (treatments T1, T2) receiving similar seasonal management and different irrigation doses. Each treatment was composed by five rows. Sixty potatoes crop were planted per row. In particular, treatments T1 was maintained under full irrigation management by supplying the volumes corresponding to the maximum crop evapotranspiration estimated between consecutive watering, whereas treatments T2 (deficit irrigation) received approximately the half of volumes provided in T1. Volumetric 
counters (precision $0.1 \mathrm{dm}^{3}$ ) allowed checking the total volume provided in the plots, during each watering. For all season, irrigation consisted on two treatments replicated five times, arranged in a complete split plot block design.

\section{Maximum evapotranspiration}

Agroclimatic data were acquired from a climate station located at $300 \mathrm{~m}$ far from the experimental site in 2014 and inside the experimental field in 2015. The station provided hourly records of solar radiation, precipitation, maximum and minimum temperature and relative humidity. From hourly records, daily maximum and minimum values of temperature and humidity were obtained. Similarly, daily radiation and precipitation were accumulated. From these records, reference evapotranspiration (ETo) was computed using the Penman-Monteith equation.

\section{Soil water retension curves, irrigation management and water contents}

Preliminarily, in laboratory the soil proprieties (saturated water content, water content at field capacity and water content at permanent welting point) were determined on soil samples, $8.0 \mathrm{~cm}$ diameter and $5.0 \mathrm{~cm}$ height collected in the field at depths $0.15,0.30$ and $0.45 \mathrm{~m}$. The water column technique performed in Buckner funnels (Dane and Hopmans, 2002), equipped with porous plates with air entry point $\mathrm{h}=-200 \mathrm{hPa}$ was used for matric potentials ranging between $0 \mathrm{hPa}$ (saturation) and about $-150 \mathrm{hPa}$, whereas the pressiometric method using the Richard apparatus (Dane and
Hopmans, 2002) was applied for soil matric potential of 330, 1,000, 3,300 and $15,000 \mathrm{hPa}$. Saturated soil hydraulic conductivity was determined by the constant head permeameter on undisturbed soil samples $8.0 \mathrm{~cm}$ diameter and $5.0 \mathrm{~cm}$ height. Spatial and temporal variability of soil water content around a single emitter, was daily monitored with a Trime TDR probe (IMKO Micromodultechnik $\mathrm{GmbH}$ ) having a precision of $\pm 0.03 \mathrm{~cm}^{3} / \mathrm{cm}^{3}$ (Douh, 2012). In each plot, soil water content was regularly measured at $15 \mathrm{~cm}, 30 \mathrm{~cm}$ and $40 \mathrm{~cm}$ depths and distance $0 \mathrm{~cm}$ and $15 \mathrm{~cm}$ and $30 \mathrm{~cm}$ from the emitter.

\section{Plant measurements}

Crop agronomic parameters mainly leaf area index, rooting depth and yield productions, were measured different plants from randomly chosen locations of each subplot, and from six plant every 8 days in 2014. In particular, after cleaning the root, they were measured and leaves were detached and their surface areas were measured with the planimetric technique implemented in the Skye Leaf version 2 software (Skye Instruments Ltd.). Leaf areas were then divided by total ground area by a plant. Thereafter, and approximately from the starting of tuber formation, around DAP 40 , tubers of plants used for the determination of LAI and root depths, were collected and weighed. In 2014, sampling was less intensive, and agronomic parameters were measured every ten days. Leaf area index was converted to CC using the following formula (Heng et al., 2009):

$$
\mathrm{CC}=1.005[1-\exp (-0.6 \mathrm{LAI})]^{1.2}
$$


At the end of the growth season, irrigation water use efficiency (IWUE) was calculated as the ratio between the final crop yield (Y) and the irrigation water supplied by the following formula:

$$
\mathrm{IWUE}=\frac{\mathrm{Y}}{\mathrm{I}}
$$

\section{evaluation}

Table 2. Summary of statistical parameters used for model evaluation.

\begin{tabular}{lcl}
\hline Statistical index & Formula & \multicolumn{1}{c}{ Indications } \\
$\begin{array}{l}\text { Root Mean Square } \\
\text { Error }\end{array}$ & $R M S E=\sqrt{\frac{\sum_{i=1}^{N}\left(X_{\text {sim }, i}-X_{o b s, i}\right)^{2}}{N}}$ & $\begin{array}{l}\text { Error expresed in the same units of } \\
\text { the considered variable }\end{array}$ \\
\hline Mean Bias Error & $M B E=\frac{1}{N} \sum_{i=1}^{N}\left(X_{\text {sim }, i}-X_{o b s, i}\right)$ & Average over- or under-prediction \\
$\begin{array}{l}\text { Nash-Sutcliffe } \\
\text { efficiency index }\end{array}$ & $E=1-\frac{\sum_{i=1}^{N}\left(X_{\text {sim }, i}-X_{o b s, i}\right)^{2}}{\sum_{i=1}^{N}\left(X_{o b s, i}-\overline{X_{o b s}}\right)^{2}}$ & $\begin{array}{l}\mathrm{E}=1 \text { (Perfect agreement); } 0<\mathrm{E}<1 \\
\text { (model suitable to reproduce } \\
\text { measured data); E < 0 (unacceptable } \\
\text { performance) }\end{array}$ \\
\hline
\end{tabular}

\section{Results and discussion}

Table 2 shows the parameters used for the characterization of the soil profile for treatment $\mathrm{T} 1$ and $\mathrm{T} 2$ during the experimental years of 2014 and 2015.

Table 2. Soil properties used to represent the soil profile in AquaCrop for T1 and T2 during the experimental year of 2014 and 2015.

\begin{tabular}{ccccccc}
\hline Horizon & Texture & Depth & $\begin{array}{c}\text { Os } \\
{\left[\mathbf{c m}^{\mathbf{3}} \cdot \mathbf{c m}^{-3}\right]}\end{array}$ & $\begin{array}{c}\text { Occ } \\
{\left[\mathbf{c m}^{\mathbf{3}} \cdot \mathbf{c m}^{-3}\right]}\end{array}$ & $\begin{array}{c}\text { Opfp } \\
{\left[\mathbf{c m}^{\mathbf{3}} \cdot \mathbf{c m}^{-3}\right]}\end{array}$ & $\begin{array}{c}\text { Ks } \\
{\left[\mathbf{c m}^{-\mathbf{1}} \mathbf{]}\right.}\end{array}$ \\
$\mathbf{1}$ & Sandy loam & $0-15$ & 0.40 & 0.28 & 0.10 & 11.00 \\
$\mathbf{2}$ & Sandy loam & $15-30$ & 0.39 & 0.28 & 0.10 & 6.40 \\
$\mathbf{3}$ & Sandy loam & $30-40$ & 0.40 & 0.28 & 0.10 & 3.80 \\
\hline
\end{tabular}

In this study, several iterations were investigated for testing the possible application of parameters of Hsiao et al. (2009). Results showed satisfactory results for wide number of these parameters. In fact, Table 3 shows the only canopy growth parameters that were modified to reproduce field measurements. The sensitivity of plant to soil water stress were chosen as 'moderately tolerant to water stress', including the soil water stress coefficient for canopy expansion, stomatal closure, and canopy senescence. 
Table 3. Coefficients for crop growth development used by AquaCrop, the regression lines (B: slope; A: intercept) and the determination coefficient $\mathrm{R}^{2}$ for the relationship between observed and simulated values in 2015.

\begin{tabular}{|l|c|c|c|c|c|c|c|}
\hline & $\mathbf{C C}_{\boldsymbol{0}}$ & $\mathbf{C C}_{\mathbf{x}}$ & $\mathbf{C G C}$ & $\mathbf{C D C}$ & $\mathbf{A}$ & $\mathbf{B}$ & $\mathbf{R}^{\mathbf{2}}$ \\
\hline $\mathrm{T} 1$ & 0.4 & 89 & 0.4 & 19 & 0.979 & 0.783 & 0.992 \\
\hline $\mathrm{T} 2$ & 0.3 & 60 & 0.19 & 8 & 0.952 & 0.254 & 0.987 \\
\hline
\end{tabular}

$\mathrm{CC}_{0}$ : Initial canopy cover; $\mathrm{CC}_{\mathrm{x}}$ : maximal canopy cover; CGC: development rate of canopy cover; $\mathrm{CDC}$ : daily coefficient decline

In order to reproduce final $Y$ for the environmental condition of the study area, different values of water productivities WP were tested.
Subsequently, a relationship between observed and estimated $Y$ for the examined $W P$ was depicted, as shown in Figure 3.
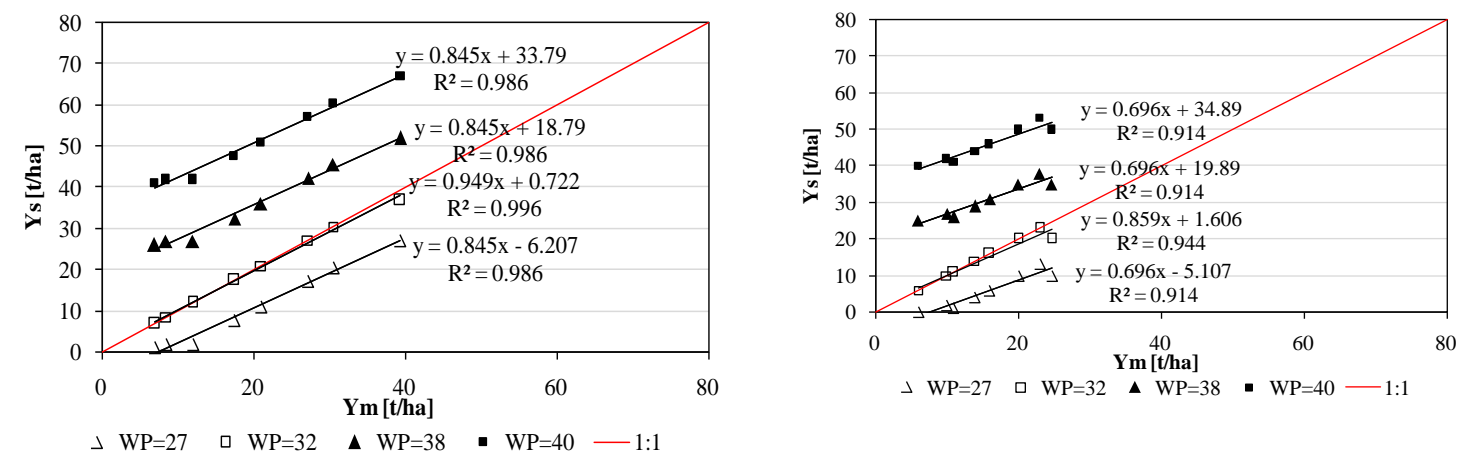

Figure 3. Relationship between simulated and measured yield productions, Ys and Ym, for the different investigated water productivities during the calibration.

Statistical analysis computed during the calibration process for water contents, canopy develpement and yield production are summarized on Table 4 .

Table 4. Statistical indices of simulated water contents, canopy cover development and simulated yield for the calibration dataset.

\begin{tabular}{|l|l|l|l|l|}
\hline \multicolumn{2}{|c|}{} & N & RMSE & E \\
\hline \multicolumn{7}{|c|}{} & \multicolumn{2}{|c|}{ Water contents } \\
\hline T1 & 347 & 0.02 & 0.03 \\
\hline T2 & 347 & 0.71 & 0.62 \\
\hline \multicolumn{7}{|c|}{} & Canopy cover development \\
\hline T1 & 16 & 3.84 & 0.98 \\
\hline T2 & 16 & 5.54 & 0.95 \\
\hline & & Yield production & 0.97 \\
\hline T1 & 8 & 2.05 & 0.80 \\
\hline T2 & 8 & 3.08 & \\
\hline
\end{tabular}


In 2014, potato crop was planted on the same field of 2015 and was used as a control test for evaluating the calibration of the AquaCrop software. Sampling was less intensive since vegetation cover was determined from a single plant at nine dates during the growth cycle. The different statistical indicators computed during the validation are presented on Table 5.

Table 5. Statistical indices of simulated water contents, canopy cover development and simulated yield for the validation dataset.

\begin{tabular}{|c|c|c|c|}
\hline & $\mathbf{N}$ & RMSE & $\mathbf{E}$ \\
\hline \multicolumn{4}{|c|}{ Water contents } \\
\hline T1 & 347 & 0.03 & 0.04 \\
\hline T2 & 347 & 0.75 & 0.51 \\
\hline \multicolumn{4}{|c|}{ Canopy cover development } \\
\hline T1 & 8 & 5.86 & 0.96 \\
\hline T2 & 8 & 7.90 & 0.86 \\
\hline \multicolumn{4}{|c|}{ Yield production } \\
\hline T1 & 8 & 2.38 & 0.95 \\
\hline T2 & 8 & 1.4 & 0.95 \\
\hline
\end{tabular}

Figure 4 shows irrigation water use efficiencies for Treatments T1 and T2 during the experimental seasons of 2014 and 2015.

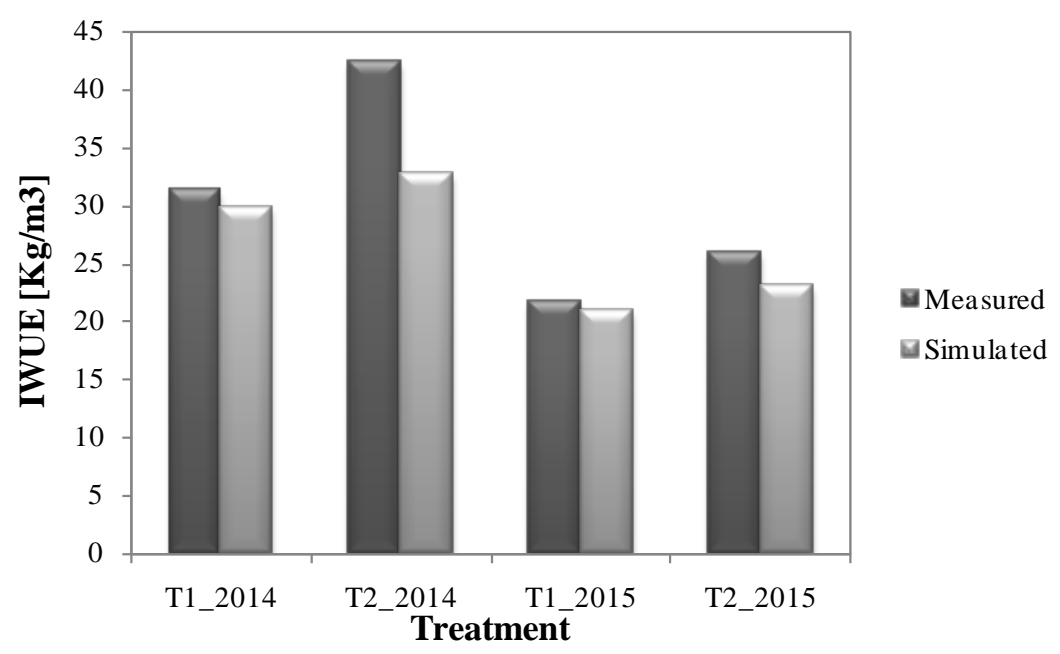

Figure 4. Irrigation water use efficiences for Treatments $\mathrm{T} 1$ and $\mathrm{T} 2$ during the experimental seasons of 2014 and 2015. 


\section{Discussion}

To assess the performance of the model in reproducing field conditions of the soil plant atmosphere system, statistical indexes for mean squared error, RMSE and Nasch coefficient were calculated.

Table 5 showed that RMSE values were always lower than $0.04 \mathrm{~cm}^{3} \cdot \mathrm{cm}^{-3}$, suggesting the goodness of fit between average moisture content in the $40 \mathrm{~cm}$ soil layer. This result was also confirmed with the Nash coefficient (Katerji Et al., 2013).

Moreover, when analyzing results from statistical indicators of canopy cover predictions presented on Table 5, it is noticed that RMSE were higher in T2 than in T1, and was in general lower than $6 \%$. Results from $\mathrm{E}$ were almost equal to one, showing that the model is well assessed to predict the vegetation development under the study area. However, the model presented a greater performance in the case of full irrigation strategy.

Moreover, Water productivity is a key factor in simulating yield production from any crops. When evaluating different values of water productivity, the adjustment function between observed and estimated productions showed in all cases a correlation coefficient greater than 0.9. However, with a $W P=38$ g.m ${ }^{-2}$ or 40 g.m ${ }^{-2}$, an overestimation was well denoted. However, for a $W P$ of 27 g.m ${ }^{-2}$, final productions were remarkably underestimated. In conclusion, a WP of 32 g.m ${ }^{-2}$ produced the lowest estimation error. Kayschap et al. (2002) reported that potato crop is classified between the characteristic values of species C3 and C4, which corresponds to water productivity between 20 and 30 g.m², respectively. Regarding yield productions, statistical indictors, computed for a $W P$ value of 32 g.m-2 shows in general RMSE values lower than $0.4 \mathrm{t} / \mathrm{ha}$. In addition, $\mathrm{E}$ was closer to one for the non stressed treatment, T1.
This results confirms that the model is well calibrated to reproduce the productive function. Moreover, performance of the model declines in a condition of water stress. In 2014, the potato crop was planted on the same field of 2015 and was used as a control test for evaluating the calibration of the AquaCrop software. Sampling was less intensive since vegetation cover was determined from a single plant at nine dates during the growth cycle. In 2014, AquaCrop was unable to reproduce the punctual dynamic of soil water content. However, simulated average values were considered acceptable.

The presence of grape of air between soil and measurement tube, observed especially during that season, could justify this inability. The analysis of statistical indicators for water contents, canopy cover and yield production confirmed the previous results of ability of the model to simulate water movement through the soil plant atmosphere system obtained in 2015. Additional calculation for mean bias error showed negative values for all the component. When it is the case of IWUE, the model underestimated field IWUE (Figure 4). Many other researches underlined the mismatch of simulated IWUE. Moreover, the discrepancy between simulated and estimated IWUE rose for treatment $\mathrm{T} 2$, implying that the model calibration should be improved, especially for stressed conditions. Likewise, Evett and Todorovic (2009) suggested that AquaCrop could be reliable in simulating WUE only under non-deficit irrigation and tended to misestimate WUE under conditions of deficit irrigation. Furthermore, Katerji et al. (2013) concluded even that AquaCrop's performance in simulating IWUE is not satisfactory in cases of severe water stress. Figure 4 shows that in general, the higher values of IWUE were associated to deficit irrigation, even if the high efficiencies connected to the water restricted regimes were counterbalanced by reduced yield and 
quality. El Mokh et al. (2014), based on experiments carried out in Southern Tunisia found similar results. However, if from one side limiting irrigation depth determines a certain increase of IWUE, from the other side produces a reduction of crop yield, with unavoidable effects on the farmer's gross revenues. For this reason, in order to identify irrigation scheduling strategies, it is necessary to monitor the climatic variables from one side, but also to make economic analysis aimed to compare the costs associated to irrigation with the benefits corresponding to the higher productions. In agreement with El Mock et al. (2004), full irrigation strategies could be recommended for irrigation of potato crop under the semi-arid climate of Tunisia, even if the possibility to reduce water supply can be envisaged when water availability is limited, but with the awareness to accept shortage of production.

\section{Conclusion}

In this study, performance of AquaCrop for simulating field conditions of water content, vegetation cover, yield production and irrigation water use efficiency was performed. RMSE values were always lower than $0.04 \mathrm{~cm}^{3} . \mathrm{cm}^{-3}$ for water contents lower than 0.06 for vegetation cover estimation. Moreover, Results from E were almost equal to one. These latter results justified that the model was well assessed to predict the soil water contents and vegetation development under the study area. However, the model presented a greater performance in the case of full irrigation strategy. When evaluating different values of water productivity, the adjustment function between observed and estimated productions showed in all cases a correlation coefficient greater than 0.9. However, with a $W P=38$ g.m $^{-2}$ or 40 g.m. ${ }^{-2}$, an overestimation was well denoted. However, for a $W P$ of 27 g.m-2, final productions were remarkably underestimated. In conclusion, a WP of
32 g.m-2 produced the lowest estimation error. Regarding yield productions, statistical indictors, computed for a $W P$

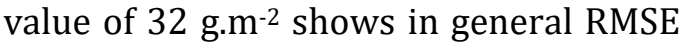
values lower than $0.4 \mathrm{t} / \mathrm{ha}$. In addition, $\mathrm{E}$ was closer to one for the non stressed treatment, T1. For irrigation water use efficiency, it was revealed that the model underestimated field IWUE. Moreover, the discrepancy between simulated and estimated IWUE rose for treatment T2, implying that the model calibration should be improved, especially for stressed conditions.

\section{Conflict of interest}

The authors declare that there is no conflict of interest.

\section{References}

Chehaibi, S.; Hamdi, W., Abroug, K. Effects of planting depth on agronomic performance of two potato varieties grown in the Sahel Region of Tunisia. Journal of Development and Agricultural Economics, v. 5, no. 7, p. 272-76, 2013.

Douh, B. Etude théorique et expérimentale de l'irrigation goutte à goutte souterraine sur une culture de maïs (Zea mays L.). Sousse, Tunisia: Higher Agronomic Institute of Chott Meriem, 2012. (Ph. D. thesis).

Droogers, P.; Hunink, J. Assessment of impact of climate change on Wheat in Armenia, Azerbaijan and Georgia. Regional Analytical and Advisory Activities Program on Developing Adaptation and Mitigation Strategies in the Agricultural Sector for Armenia, Azerbaijan and Georgia. Future Water, 2012.

Eldredge, E. P.; Holmes, Z. A.; Mosley, A. R.; Shock, C. C.; Stieber, T. D. Effects of transitory water stress on potato tuber stem-end reducing sugar and fry color. American Potato Journal, n. 73, p. 51730, 1996. 
Farahani, H. J.; Izzi, G.; Oweis, T. Y. Parameterization and evaluation of the AquaCrop model for full and deficit irrigated cotton. Agronomy Journal, no. 101, p. 469-476, 2009.

Heng, L. K.; Hsiao, T.; Evett, S.; Howell, T.; Steduto, P. Validating the FAO AquaCrop model for irrigated and water deficient field maize. Agronomy Journal, no. 101, p. 488-498, 2009.

Hsiao, T. C.; Heng, L.; Steduto, P.; RojasLara, B.; Raes, D.; Fereres, E. AquaCropThe FAO crop model to simulate yield response to water: III. Parameterization and testing for maize. Agronomy Journal, no. 101, p. 448-459, 2009.

Katerji, N.; Campi, P.; Mastrorilli, M. Productivity, evapotranspiration, and water use efficiency of corn and tomato crops simulated by AquaCrop under contrasting water stress conditions in the Mediterranean Region. Agricultural Water Management, no. 130, p. 14-26, 2013

Kayshap, P. S.; Panda, R. K. Effect of irrigation scheduling on potato crop parameters under water stressed conditions. Agricultural Water Management, no. 59, p. 49-66, 2002.

Kayshap, P. S.; Panda, R. K. Effect of irrigation scheduling on potato crop parameters under water stressed conditions. Agricultural Water Management, no. 59, p. 49-66, 2002.
Nash, J. E.; Sutcliffe, J. V. River flow forecasting through conceptual models. Part I: A discussion of principles. Journal of Hydrology, no. 10, p 282-290, 1970.

Shock, C. C.; Zalewski, J. C.; Stieber, T. D.; Burnett, D. S. Impact of early-season water deficits on Russet Burbank plant development, tuber yield and quality. American Potato Journal, no. 69, p. 793-803, 1993.

Steduto, P.; Hsiao, T. C.; Raes, D.; Fereres, E. AquaCrop-The FAO crop model to simulate yield response to water: I. Concepts and underlying principles. Agronomy Journal, no. 101, p. 426-437, 2009.

Todorovic, M.; Albrizio, R.; Zivotic, L.; Abi Saab, M. T.; Stöckle, C.; Steduto, P. Assessment of AquaArop, CropSyst, and WOFOST models in the simulation of sunflower growth under different water regimes. Agronomy Journal, no. 101, p. 509-521, 2009.

Willmott, C. J.; Wicks, D. E. An empirical method for the spatial interpolation of monthly precipitation within California. Physical Geography, no. 1, p. 59-73, 1980.

Wright, J. L.; Stark, J. C. Potato. In: Stewart, B. A.; Nielsen, D. R. (Eds). Irrigation of Agricultural Crops: Agronomy. Madison, Wisconsin: ASACSSA-SSSA, 1990. (Monograph, 30). 